\title{
RESEÑA
}

\section{KISSINGER, H. (2016). Orden mundial: Reflexiones sobre el carácter de los países y el curso de la historia, Pengüin Random House Grupo \\ Editorial S.A.U., Barcelona. Tercera reimpresión, Ed. Debate. Traducción Teresa Arijón, Colombia, febrero de 2020}

No se puede leer a Henry Kissinger sin la inevitable curiosidad que despiertan su condición de ex Secretario de Estado de los Estados Unidos y su indiscutible erudición sobre relaciones internacionales y geopolítica.

Su figura como político no deja de ser controversial. Perteneció al gabinete de Nixon y de Ford de manera continua; primero como consejero de Seguridad Nacional y luego como jefe de la diplomacia norteamericana. En su gestión debió lidiar con el final de la guerra de Vietnam y con la guerra del Yom Kippur.

La organización Nobel le concedió el galardón de paz de 1973 por su vocación negociadora. Sin embargo, sus críticos le endilgan que los esfuerzos por alcanzar un alto al fuego en Vietnam sólo dieron frutos dos años después del Nobel cuando se firmaron finalmente los acuerdos de París en 1975.

De otro lado, diversos movimientos sociales y analistas latinoamericanos cuestionan la vocación pacifista de Kissinger; su paso por la Secretaría de Estado se dio en tiempos que dictadores militares frenaron los procesos democráticos en Sudamérica; algunos de ellos con el apoyo de la CIA.

Pero, hablemos de la obra. Este es un libro escrito por un hombre retirado pero lúcido; desconectado de las salas de crisis de la Casa Blanca pero que, evidentemente, no ha perdido el hilo de los acontecimientos que en las últimas décadas han tejido el entramado de la globalización.

Y, aunque no se trata de una biografía, el último libro del nonagenario Kissinger (nacido en 1923) trae grabado el sello de su identidad personal: representante fiel del realismo político, vocero de la política exterior de la mayor potencia geopolítica y militar del último siglo y académico formado en los principios westfalianos. Y son precisamente Westfalia y sus principios los que inspiran metodológicamente esta obra.

Este libro no es una referencia neutral sobre geopolítica, es evidente que su rigor se ve permeado por un pensamiento realista y, de modo muy marcado, por su posición interesada desde las huestes de la potencia norteamericana. Cita a Westfalia, a veces con rigor, a veces con amañado interés imperial.

\section{¿De dónde venimos?}

Orden Mundial es un libro escrito con profunda claridad académica; como si el catedrático hubiese preparado sus clases para explicar el mundo desde una perspectiva geopolítica en su evolución histórica y territorial.

La narrativa histórica comienza en un mundo eurocéntrico controlado desde una 
simbiosis entre el Sacro Imperio Romano y las élites territoriales del viejo mundo; una amalgama entre casas reales y el Papa. Un constante diluvio de matrimonios y divorcios entre el heredero al "trono de San Pedro" y los -casi siempre- efímeros reyes europeos.

Dicho mundo sufre una transformación radical con la paz de Westfalia (1648), la cual se convierte en causal de divorcio definitivo entre la iglesia católica y los gobernantes laicos de los nacientes Estados nacionales. Para el autor, Westfalia es la semilla de la modernidad geopolítica.

Sin embargo, Kissinger es claro en señalar que el mundo de aquella época se extiende territorial e ideológicamente más allá de la Europa westfaliana. China, India, Japón y la Rusia euroasiática hacían parte de un mundo ajeno a Westfalia.

Se trata de culturas milenarias difíciles de entender para aquellos que cultivaban lo que con el tiempo se denominó Occidente. Al otro lado del Occidente estaba el Oriente, o sea, "lo otro", lo indescriptible, lo inexplicable.

La paz de Westfalia fue convocada por el Sacro Imperio Romano y sus dos más enconados rivales, Francia y Suecia, después de varios lustros de la llamada Guerra de los Treinta Años.

No existió una única negociación, fueron varios los acuerdos firmados. Las potencias católicas, con casi 200 delegados, se reunieron en la ciudad católica de Münster, mientras las protestantes lo hicieron en Osnabrück -ciudad dividida entre católicos y luteranos-.

La paz de Westfalia derivó en tres acuerdos independientes, firmados en diferentes momentos y lugares. El primero permitió el reconocimiento de Holanda por parte del reino de España (la paz de Münster de enero de 1648); mientras los dos acuerdos finales (octubre), constituyeron el cuerpo central de lo negociado (Tratado de Münster y Tratado de Osnabrück).

En principio Westfalia no significó una novedad; se trataba como en otros acuerdos, de "verdadera y sincera paz y amistad cristiana, universal y perpetua" (Kissinger, 2016: 37). Sin embargo, Westfalia sentó las bases de un nuevo orden internacional centrado en las relaciones entre Estados, en lugar de dinastías, casas reales o inclinaciones religiosas. Nacía el Estado soberano.

Ante la desaparición de la iglesia como fuente universal de legitimidad, la multiplicidad y diversidad se convirtieron en los principios del nuevo sistema. Cada país signatario podría darse su propio régimen y elegir la religión que profesaría. Incluso, algunas cláusulas establecían el derecho de minorías a preservar sus creencias religiosas sin que ello debilitara la identidad del Estado.

Durante los siguientes siglos, los principios westfalianos se expandieron por todo el planeta, especialmente después de los procesos de descolonización de África, Asia, Oceanía y América. Las élites de los nacientes países fundaron sus Estados tomando como referente el modelo consolidado en Europa Occidental. El nuevo mundo (América) y otras naciones emergentes son ramas del árbol genealógico de Westfalia.

Tomando como eje de análisis a Westfalia, Kissinger interpreta la historia de diversos macro-territorios, buscando explicar cómo ciertas dinámicas dialécticas explican su evolución hasta el mundo de hoy.

Una Rusia zarista se erige y consolida como contrapeso de poder en Europa, su 
enorme tamaño y ambiciones de expansión le dan sentido a su régimen. Para Catalina la Grande, la autocracia era el único régimen posible para mantener unido tan vasto territorio. Si bien la revolución bolchevique dio fin a la monarquía rusa -el régimen del Zar-, el gobierno revolucionario preservó, en criterio del autor, el espíritu de la Gran Madre Rusia.

En esta misma dirección, el autor recorre la ruta del islam, desde el imperio Otomano hasta el archipiélago de territorios y naciones sunitas y chiitas. La primavera árabe aparece como un desarrollo natural de un mundo islámico que por diferentes caminos conecta con Occidente. Reivindicaciones sociales y aspiraciones de democracia se mezclan con confrontaciones religiosas y diferentes interpretaciones de la Yihad.

La compleja diversidad de Asia se exhibe con un Japón que muta de imperialista a bastión de Occidente en el Pacífico, con una China compleja y autárquica que evoluciona hasta convertirse en la potencia que es hoy. Y todo esto, en un entramado de alianzas y confrontaciones que, según Kissinger, se apoyan o contrastan con los principios de Westfalia.

No se puede cerrar este componente de la reseña sin resaltar el interés del autor por legitimar el actuar de los Estados Unidos a lo largo de dos siglos. La potencia norteamericana se muestra westfaliana en cada uno de sus actos, con propósitos superiores de paz y convivencia. De hecho, de manera debatible, el ex Secretario de Estado se esmera por convencernos del supuesto espíritu de no injerencia de la nación norteamericana desde su fundación.

Es difícil pensar que el autor fue descuidado o negligente al omitir las diversas intervenciones interesadas de Estados Unidos en conflictos y revoluciones que se vivieron a lo largo y ancho del planeta, especialmente en Asia, Medio Oriente, Golfo Pérsico y América Latina. Se trata de una larga lista de actuaciones en las cuales la potencia norteamericana evidenció sus intereses estratégicos a costa del principio de no injerencia y libre determinación de los pueblos.

\section{¿Para dónde vamos?}

El final de la guerra fría nos coloca en el presente. Previo a ésta, el liderazgo norteamericano delineado por T. Roosevelt, W. Wilson y F. Roosevelt permeó a Occidente. La emergente potencia del siglo XX esbozó principios alrededor de los cuales giraría el orden internacional.

“Actuar por toda la humanidad”, señala Kissinger. Estados Unidos ha desempeñado un papel decisivo en la configuración del orden mundial bajo la convicción de que sus principios nacionales tienen valor internacional. En esta parte de la obra el autor legitima el papel mesiánico de los Estados Unidos; la metáfora del pueblo elegido se combina con la misión salvadora y universal del cristianismo. Negando cualquier supuesto interés nacional, Kissinger defiende la "vocación" norteamericana de expandir sus valores, los cuales "los otros pueblos aspiran a compartir" (Kissinger, 2020: 239).

La obra es silenciosa sobre las realidades complejas al interior de la sociedad norteamericana y ello le permite afincar sus argumentos alrededor de los principios de libertad de culto, de acción y de expresión, como los motores del actuar de los Estados Unidos en el exterior. Contrario al Viejo Mundo que vio en el Nuevo Mundo una oportunidad para el saqueo de riquezas, Estados Unidos sería el mensajero de la buena 
nueva.

Lo anterior evidencia las motivaciones políticas del erudito que se apalancó en su profunda comprensión de la paz de Westfalia para narrar con cierto interés el desarrollo del mundo actual, a partir del principio de la no injerencia.

Sin embargo, la narrativa de esta obra también es crítica y compleja, mostrando a unos Estados Unidos ambivalentes. Inspirados en el ánimo de compartir sus valores, los norteamericanos se han posado sobre todo un continente y han sido protagonistas de los acontecimientos más relevantes del planeta en más de un siglo. Todo, supuestamente, "abjurando al mismo tiempo de los principios imperiales".

Particularmente, en el marco de la guerra fría, Kissinger es bastante crítico ante la pérdida de cohesión nacional y de coherencia en el exterior. Esa es la realidad que hereda Nixon en 1969. También podríamos decir que es la situación en la que el autor de esta obra se une al sanedrín del gobierno norteamericano. Es el momento de Kissinger.

Esta obra señala a Nixon como eje de una nueva concepción de equilibrio de poder pasando del modelo de T. Roosevelt que pone a Estados Unidos como guardián de la balanza, a una nueva concepción en la que Norteamérica hace parte del equilibrio fluido de la misma balanza.

Bajo este principio, Estados Unidos realineó los pesos de la balanza, colocándose más cerca de la Unión Soviética (evitando cualquier confrontación directa) y de China. Los norteamericanos estaban más cerca de las potencias comunistas, que lo que estas últimas estaban entre sí. Se deduce de esta narración, que Nixon delineó el final de la guerra fría y el devenir de la globalización.

En este punto la obra nos coloca en el presente. Después de un corto reconocimiento a Reagan -en palabras de Kissinger, el presidente más acorde a su época, para cerrar el ciclo de la guerra fría, el autor establece algunos lineamientos de futuro. La prospectiva hace su aparición.

Cada época tiene un sello propio. La religión delineó la cosmovisión previa a Westfalia; la razón iluminó a los tiempos de la Ilustración y el nacionalismo marcó los siglos XIX y XX. Ahora, la ciencia y la tecnología trazan las líneas del devenir. ¿Quo Vadis, humanidad?

El mundo se halla aquí luego del periodo en el que el orden mundial combinaba incipiente idealismo norteamericano con elementos tradicionales de equilibrio de poder. Es evidente la doble intención del autor: desconocer los aportes de otras regiones, como la Europa de la segunda posguerra mundial, a la paz mundial y minimizar los intereses norteamericanos en materia de equilibrio de poder.

De dicha época heredamos la proliferación de las armas nucleares y el auge de la ciber-tecnología para un mundo más interconectado. De igual manera, parece existir un reconocimiento explícito de valores supuestamente universales: paz, democracia, derechos humanos. Sin embargo, su interpretación y valoración difieren de región a región. Un Occidente más o menos delineado le da una interpretación, pero en China, Rusia, India o naciones musulmanas, la naturaleza de estos conceptos cambia.

Y allí, una polémica y profunda conclusión del autor: "El resultado no es simplemente una multipolaridad, sino un mundo de realidades crecientemente contradictorias" (Kissinger, 2020: 365). 
En un mundo en el que las armas pueden destruir al planeta y las interacciones entre los diversos sistemas de valores se vuelven intrusivas, los métodos tradicionales se quedan cortos para mantener el equilibro de poder.

Para entender la dificultad de mantener un equilibrio en el futuro, Kissinger señala cuatro elementos claves: insuficiencias en la naturaleza misma del Estado nación; incongruencia entre las organizaciones multilaterales (del orden interestatal) y la realidad de la globalización; ausencia de mecanismos efectivos de diálogo y concertación entre las potencias; y el rol ambivalente de los Estados Unidos.

Estos cuatro pilares serían centrales para la reevaluación del equilibrio de poder. Y con esta idea final, Kissinger deja ver a toda luz su espíritu realista, más que idealista y su postura pro norteamericana por encima de los aclamados a lo largo de la obra, principios Westfalianos.

Sin embargo, podemos estar de acuerdo o no con el ex Secretario de Estado, pero su lucidez al final del camino de la vida, su experiencia y trayectoria lo hacen un autor inevitable de leer.

Para ser su pupilo, hay que leerlo. Para ser su contradictor, hay que leerlo.

Giovanny Cardona Montoya, Vicerrector Académico, Institución Universitaria CEIPA. Economista de la Universidad Estatal de Kiev, Magister en Análisis de Problemas Políticos, Económicos e Internacionales de la Universidad Externado de Colombia; Magister en Integración y Cooperación Internacional de la Universidad Nacional de Rosario (UNR), Argentina; Doctor en Ciencias Pedagógicas de la Universidad de Pinar de Río, Cuba. Líder del Grupo de Investigación Orygen, categoría A de Minciencias, Colombia. Correo electrónico: giovanny.cardona @ ceipa.edu.co https://orcid.org/0000-0003-2253-3580.

\section{Cómo citar}

CARDONA MONTOYA, G. (2021). Reseña Kissinger, H. (2016). Orden mundial: Reflexiones sobre el carácter de los países y el curso de la historia. Pengüin Random House Grupo Editorial S.A.U., Barcelona. Tercera reimpresión, Ed. Debate. Traducción: Teresa Arijón, Colombia, febrero de 2020. Revista Integración Y Cooperación Internacional, 32 (ene-jun), 72-76 